\title{
EXHIBITS AND APPENDICES
}

\section{Exhibits}

1.1 Theory-driven and practice-driven research 3

1.2 "Sweet spot" management research 7

1.3 The knowledge-generating value stream 12

1.4 Collaborative research and interactive knowledge exchange 16

2.1 Ontology, epistemology, methodology, and some practical questions 23

2.2 Burrell and Morgan's sociological paradigms 25

2.3 Some major research schools of thought 28

2.4 Van de Ven's engaged scholarship diamond 30

$2.5 \quad$ Engaged scholarship continuum 31

3.1 The knowledge-generating value stream (full) 43

3.2 Networks underlying the knowledge-generating value stream (simplified depiction) 51

5.1 Sweet spot research and the sourcing dimension 71

5.2 Three sourcing/framing strategies 73

5.3 Some practical problems and their theoretical frames 75

5.4 Process models incorporate time 79

5.5a Stages of corporate citizenship 81

5.5b Developmental drivers of corporate citizenship 81

5.6 Two types of theory-practice connections 85

5.7 Characteristics of good theory and its application for practice 88

5.8 Network model of organization 90

6.1 Sweet spot research standards 95

6.2 Pattern matching in sweet spot research 98

$\begin{array}{ll}\text { 6.3 Sample agility profile } & 100\end{array}$ 
6.4 Jazz in the empty spaces 101

$\begin{array}{lll}6.5 & \text { Assessing organization change } & 113\end{array}$

7.1 Communicating with the consumers of research 119

7.2 How findings contribute to theory and practice 122

7.3 Comparing traditional and sweet spot stories $\quad 127$

$\begin{array}{lll}7.4 & \text { An agility storyboard } & 128\end{array}$

8.1 The research role system 143

9.1a Your journey from the ivory tower to the real world (steps 1-6) 166

9.1b Your journey from the ivory tower to the real world (steps 7-12) 167

\section{Appendices}

$\begin{array}{lll}1.1 & \text { Resources on useful research } & 20\end{array}$

8.1 "Issues" in Organization Research and How to Respond 156

9.1 Resources on research careers $\quad 171$ 